\title{
Las prácticas académicas y culturales de los jóvenes como modos de apropiación del espacio universitario
}

\section{The academic and cultural practices of young people as modes of appropriation of the university space}

DOI: https://doi.org/10.32870/dse.v0i24.969

Erika Yurizan Hernández Dávila*

José Luis Suárez Domínguez**

Alim Getze Mani Eden Vasquez Feria***

\begin{abstract}
Resumen
La juventud y la vida escolar son dos escenarios que convergen en los estudiantes como agentes sociales participantes del campo universitario. A partir de la perspectiva de Pierre Bourdieu, el presente artículo aborda la heterogeneidad de las estrategias académicas y culturales de los jóvenes universitarios durante el primer año de estudios en la Universidad Veracruzana, principal institución pública del estado de Veracruz, México. La condición juvenil desempeña un papel central en la capacidad de agencia de los estudiantes, quienes experimentan ese periodo inicial decisivo para la configuración de sus trayectorias escolares dentro de la educación superior. En el nivel metodológico, realizamos un estudio cuantitativo, exploratorio y comparativo con seis disciplinas académicas para analizar las prácticas culturales y académicas de estos actores tanto dentro como fuera del espacio escolar. Con el uso del cuestionario recuperamos la información empírica y con el empleo del análisis factorial y el análisis bivariado, emprendimos el análisis de los resultados. Como principal hallazgo, se reporta una relación estrecha entre las prácticas académicas y socioculturales y las disciplinas a las que los estudiantes ingresaron en la Universidad Veracruzana en el primer año de estudios. La condición juvenil es el correlato de las estructuras disciplinarias y lo que se considera valioso en estas comunidades.
\end{abstract}

Palabras clave: Juventud - estudiante - educación superior - disciplina - primer año.

\section{Abstract}

Youth and school life are two scenarios that converge in students as social agents who take part in the university field. Based on Pierre Bourdieu's approach, this article addresses the heterogeneity of the aca-

* Maestra en Investigación Educativa. Investigadora, Universidad Veracruzana, Xalapa. México. yuritzan@hotmail.com

** Doctor en Sociología. Línea de Investigación: Actores sociales en educación. Investigador en el Instituto de Investigaciones en Educación, Universidad Veracruzana, Xalapa. México. Isuarez@uv.mx

*** Maestro en Ciencias Sociales. Línea de investigación: Actores sociales, disciplinas académicas. Investigador en el Instituto de Investigaciones en Educación, Universidad Veracruzana. Xalapa, México. alivasquez@uv.mx 
demic and extracurricular strategies of young university students during their first year at Universidad Veracruzana, the main public university in the state of Veracruz in Mexico. The youth condition plays a central role in the capacity for agency of students who experience an initial period that is decisive for the shaping of their trajectories through higher education. We conducted a quantitative, exploratory, and comparative study of six academic disciplines to analyze the cultural and academic practices that students carry out both inside and outside of school, using a questionnaire to retrieve empirical information about the students as well as factor and bivariate analysis to analyze the results. Our main finding was a close link between academic and sociocultural practices and the disciplines that students studied in their first year at Universidad Veracruzana in the first year of studies. This relationship goes through the youthful condition of these social actors.

Keywords: Youth - student - higher education - discipline - first year.

\section{Introducción}

La juventud es una construcción social que depende del contexto sociocultural en el que se ubican quienes detentan esa condición. Bourdieu (2002) señala que la juventud es un concepto manipulado y manipulable, construido por la sociedad. Es decir, la sociedad es la encargada de regular su apreciación. Si bien la edad es un elemento clave en la concepción tradicional de la juventud, no la determina (Pérez, 2017; Gómez Morin, et al., 2018). En ese sentido, la juventud está relacionada más con el reconocimiento social que con cuestiones meramente biológicas.

La diversidad de contextos sociales y culturales define a la juventud como una construcción relativa, que más allá de la edad se conforma por rasgos históricos, regionales, institucionales, en suma, sociales en un sentido amplio. Uno de los contextos de nuestro interés en este artículo se refiere al campo universitario. La noción de campo es definida por Bourdieu (2007) como el conjunto de relaciones objetivas que tienen lugar dentro de un espacio social, en donde los agentes que participan en él crean un sentido práctico; es decir, una capacidad estratégica desplegada según las posiciones que ellos ocupan dentro del campo. El sentido práctico se adquiere a través de la socialización con pares y otros actores, y se observa mediante aquellas prácticas que muestran que los agentes han sido capaces de comprender el espacio social, de apropiarse de él gracias al habitus que se conforma en dicho espacio. Este primer conjunto de conceptos orienta al presente trabajo.

El campo como noción relativa al espacio social representa a todo aquel contexto donde existe un interés colectivo por algo. Este interés, definido como la Illusio o la propensión de los agentes a invertir su tiempo e iniciar trayectorias en un campo específico (como el religioso, el político, el artístico, entre otros), (Bourdieu, 1995), es el resultado de un proceso de socialización, en cierto modo biográfico, que define tales trayectorias. La Illusio está detrás de la construcción de expectativas de quienes aspiran a formar parte de dicho campo. De este modo, las 
expectativas y las trayectorias se convierten en unidades de análisis en el trabajo investigativo, donde las prácticas que llevan a cabo los agentes son de especial interés.

En el campo universitario ocurre algo similar. Los estudiantes forman parte de comunidades disciplinarias representadas por las carreras que cursan. Estas comunidades tienen sus propios ritos y creencias, producen y reproducen prácticas que las distinguen de otras. En suma, tienen definidas, mediante la socialización, sus rutas de construcción simbólica. Vale decir que las prácticas académicas que llevan a cabo los estudiantes en el contexto de sus disciplinas representan un tipo de prácticas culturales que toman forma según la construcción colectiva de aquello que se considera valioso en esos espacios sociales.

Esta primera aproximación a la noción de campo nos permite articular uno de los aspectos que dieron origen a nuestro estudio. Los estudiantes que ingresan al campo universitario en nuestro país son jóvenes, y este fenómeno configura una situación específica. El tratamiento de esta condición requiere la recuperación de una noción de juventud, actualizada, problematizada y compleja. En ese sentido, incorporamos la perspectiva de la juvenología representada, entre otros autores, por Reguillo (2017), Suárez (2017) y Urteaga y Moreno (2020), quienes advierten que la juventud está atravesada por un contexto social, cultural e histórico. Esta forma de concebir a la juventud es útil para nuestro propósito, entre otras cosas, porque introduce una dualidad al analizar las prácticas de los agentes estudiantiles en el campo universitario. Este es el principio básico del problema de la investigación, como veremos más adelante.

En tanto agentes, la dualidad que enfrentan con respecto al campo escolar se refleja, por un lado, en su condición escolar, donde se encuentran regulados por las disposiciones propias de ese espacio; por el otro lado, en su condición de jóvenes, la cual se extiende más allá de los límites de lo escolar e implica la influencia de contextos diversos. Por ello, nos referimos a estos actores como jóvenes universitarios. Esta dualidad configura procesos identitarios que, inconscientemente, generan un habitus o conjunto de disposiciones para la práctica (Bourdieu, 2007). Los jóvenes se adaptan tanto al espacio social universitario como a los contextos sociales, familiares, religiosos, políticos y culturales en toda su extensión.

Esta condición dual influye en el primer año de estudios universitario, toda vez que en ese periodo los estudiantes están pasando por un proceso de integración al medio escolar, lo que implica reconocer los patrones culturales, académicos, de interacción social, entre otros, propios de la vida universitaria. Las prácticas que los jóvenes llevan a cabo están reguladas, entonces, por una relación entre lo sociocultural y lo académico según las disciplinas en las que ellos se han ubicado durante ese periodo. Tenemos así los referentes básicos de nuestro estudio.

Para algunos autores, la juventud y la entrada en el espacio social universitario es el momento de las "primeras veces": primeras salidas, primera experiencia de vivir solos en una ciudad a veces desconocida, la entrada a redes académicas, de pares, con grupos culturales y sociales con distintas orientaciones y objetivos (De Garay, 2004; Suárez, Vásquez, 2021; Soto, 2021). 
El primer año de estudios se conoce como el periodo en el que se descubren las reglas de juego del espacio universitario. Es el universo desconocido en el que ocurren múltiples interacciones y se adquiere la entrada al campo (De Garay et al., 2017; Guzmán, 2017; Silva, 2012).

Situados en el contexto escolar, analizamos las relaciones que los estudiantes establecen con diversos actores y en diversos espacios en el ámbito de las disciplinas a las que ingresan en la universidad. La entrada en contacto de los jóvenes universitarios con sus disciplinas es un proceso que comienza con el ingreso a la universidad y en el transcurso del primer año de estudios se entrecruzan aspectos sociales, académicos y simbólicos que definen la pertenencia de los agentes y configuran sus disposiciones y prácticas. En el contexto de las disciplinas, los estudiantes adquieren códigos de lenguaje pertinentes y reconocidos en cada una de las comunidades académicas en las que ellos participan (Vinck, 2014). Pero también adquieren, ajustan o consolidan un modo de organizarse en relación con las demandas de la propia disciplina, sobre todo en cuanto a las actividades académicas y culturales se refiere.

En este artículo trabajaremos con una población escolar de 318 estudiantes que concluyeron su primer año de estudios en seis disciplinas en la Universidad Veracruzana. Como apuntamos, los referentes básicos son, en términos de espacio social y temporalidad, el primer año de estudios universitario; y en términos de construcción analítica, las prácticas socioculturales y académicas de los actores estudiantiles en el contexto de las disciplinas de adscripción.

\section{Breve estado del arte y perspectiva teórica asumida en el problema de investigación}

Dos relaciones de análisis orientaron esta investigación y originaron las preguntas que abordaremos en el texto. La primera relación se refiere a la forma en que los estudiantes experimentaron el primer año universitario en sus disciplinas a partir de un conjunto de prácticas académicas, entendidas éstas como las actividades que cumplen un doble propósito. Por un lado, atienden los requerimientos normativos de la clase escolar, los cuales se configuran de un modo distinto en cada disciplina; por otro lado, tales prácticas propician una mayor socialización con otros actores. Las prácticas académicas se convierten en medios para la socialización y, por lo tanto, para la apropiación de las reglas de juego que están presentes en los espacios disciplinarios.

Los estudiantes organizan en diferente forma el tiempo y las actividades escolares. Según Bourdieu (2007), estos son dos referentes básicos en la estructura social de los agentes. Las prácticas académicas reflejan el punto que articula a los agentes con las estructuras sociales: la escuela y sus requerimientos específicos en cada disciplina (estructura social), y los estudiantes, quienes organizan sus prácticas académicas para atender tales requerimientos (agencia social).

La segunda relación se refiere a cómo se expresó la dimensión sociocultural en ese periodo, tanto dentro como fuera del contexto escolar. Una definición específica de práctica cultural se encuentra en Canclini (2012), Mantecón (2014) y Giesler y Thompson (2016), quienes coinciden en que las prácticas culturales están encaminadas a la apropiación de los bienes simbólicos dis- 
ponibles no sólo en el mercado de tales bienes, tradicionalmente marcados por el proceso de producción, circulación y consumo, sino también en aquellas actividades de consumo cultural donde los agentes sociales participan activamente. En ese sentido, no toda práctica es cultural, ni está encaminada específicamente a la apropiación de dichos bienes.

Ambas relaciones fueron analizadas como dimensiones constitutivas del primer año de estudios, articuladas por un eje común. Este eje se conforma por el hecho de que las prácticas académicas y culturales, de acuerdo con Bourdieu, son actividades que llevan a cabo los agentes sociales con la finalidad de desplegar un sentido del juego dentro del espacio social en el que ellos conviven. Este sentido práctico tiene así un doble propósito en este artículo; por un lado, es un productor de prácticas, las incentiva, las genera mediante una socialización; por otro lado, es el resultado de una convivencia en el espacio escolar, de ahí que refleje el proceso mediante el cual puede comprenderse cómo los estudiantes se integran a sus comunidades disciplinarias.

En cuanto a la primera relación analítica, cabe señalar que en la producción investigativa no predominan estudios que asocien las prácticas académicas con el primer año universitario. Suelen enfocarse más a las trayectorias escolares y al desempeño escolar como dos fenómenos que se explican a partir de la relación entre escuela y estudiantes, sin tomar en cuenta las características relacionadas con el contexto de los jóvenes.

Entre los estudios más sobresalientes que en México y América Latina analizan a los jóvenes universitarios y sus estrategias de socialización cotidiana con sus pares (muchos de ellos provenientes de zonas geográficas con diversas costumbres y prácticas), con su contexto social próximo y con sus grupos de pertenencia, se encuentran los de Reguillo (2017), Carli (2012), Bendit y Miranda (2017), Soto (2021). Este grupo de autores observa la capacidad estratégica de los estudiantes para construir un sentido de pertenencia a la vida universitaria y a los desafíos que esto conlleva. En estos trabajos hay un enfoque histórico y biográfico para dar cuenta del proceso de socialización y de apropiación de la vida universitaria en su dimensión académica.

De manera más reciente, algunos estudios a nivel internacional han abordado la brecha que existe entre aquello que los estudiantes deberían saber para realizar tareas y actividades académicas y aquello que los estudiantes realmente saben o dominan durante el primer año (Tevis, 2020). Tevis encuentra que los estudiantes carecen de ciertos códigos lingüísticos relativos a la disciplina y cierta ineficacia para solicitar ayuda en sus actividades de formación, lo cual influye en el proceso de integración en el primer año universitario.

Lo mismo ocurre con el estudio de Lee-Jonhson (2015), quien identificó que los estudiantes construyen más oportunidades dentro del contexto académico en la medida en que ellos cuentan con más recursos de socialización traducidos en interacciones con amigos, pares y otros actores, no solo en relación con la escuela sino también en otros espacios. Esta tendencia se refleja en el aprendizaje y en la integración al medio escolar. 
Un estudio de referencia para nuestro artículo fue el de O'Brien, quien identificó que las disciplinas de adscripción regulan las prácticas académicas de los estudiantes. Algunas disciplinas incrementan la probabilidad de que los estudiantes entren en contacto con prácticas como la asistencia a conferencias o la adquisición de recursos digitales. Se menciona la importancia de ser "consumidores de conferencias" como parte de la integración al contexto escolar (O’Brien, 2019).

Con respecto a la segunda relación de análisis del problema de investigación, identificamos una literatura prolífica que asocia a las prácticas escolares como prácticas culturales, aunque a menudo se omite que las disciplinas tienden a valorar de modo diferente estas experiencias escolares. Uno de los autores más representativos en la relación disciplina y prácticas culturales es De Garay, quien utiliza un marco teórico proveniente de la antropología para ver al consumo cultural como un evento que está detrás de la construcción de trayectorias escolares de los estudiantes universitarios. Tanto el consumo interno como externo a la institución, propicia, no solo un mejor desempeño entre quienes lo llevan a cabo sino también un modo específico de reconocer los patrones simbólicos que están en la base de cada disciplina (De Garay, 2017).

Lo anterior nos conduce al estudio de Amado, quien identificó que los estudiantes universitarios han iniciado una nueva tendencia en las prácticas culturales mediante el uso del celular y otros dispositivos, en los cuales el consumo musical y de las series se convirtieron en el contenido cultural predominante (Romero, 2020). Esta misma idea está presente en la Encuesta Nacional sobre Consumo Cultural, emprendida por la UNAM, donde se aprecia un cambio radical en las formas de consumo, de las prácticas culturales en términos generales y de las dinámicas e inversión del tiempo destinado a estas actividades (INEGI, 2012).

Un elemento común en los estudios mencionados es el hecho de que hay una relación proporcional entre las prácticas culturales y la integración y el desempeño de los estudiantes en el contexto de cada una de sus disciplinas de adscripción. De este modo, a mayor inversión de tiempo en actividades culturales mayor es el proceso de adaptación en el primer año.

En una perspectiva internacional, el estudio de Serna et al. (2018) nos muestra cómo las prácticas de consumo de los jóvenes afectan a los sistemas social y educativo como dimensiones de la vida estudiantil. Se trata del mismo hallazgo identificado en los estudios nacionales. En el caso peruano, el trabajo de Duche y Andía (2019) concluye que los estudiantes universitarios relacionan lo cultural con lo artístico, histórico y tradicional como parte de la cultura local, construcciones previas a su entrada a la universidad. Las mujeres tienen mayor actividad cultural que los hombres, y los eventos más consumidos son el cine y la música. Las áreas con mayor consumo son las de ingenierías y la salud.

Se observa que en algunos estudios, como los de Epp et al., la asociación entre prácticas culturales y escuela pasa por la relación con otros elementos identitarios, tal es el caso de la vestimenta como un modo de conformar una cultura juvenil-escolar, que puede considerarse como 
una relación entre lo simbólico juvenil y lo simbólico escolar (Epp et al., 2020). Al fin de cuentas, la universidad es un espacio simbólico que crea una proyección social, al mismo tiempo que es un espacio de proyección profesional (Canclini, 2012; Suárez, 2017).

Uno de los elementos que se han incorporado en los estudios sobre prácticas culturales en la última década es el de las redes sociales como medio para el consumo. Según McEwan (2011), las plataformas de redes sociales producen un capital social online, que contribuye en la integración a la comunidad universitaria. Las plataformas de redes sociales favorecen el sentido de pertenencia al incrementar la probabilidad de asistencia a eventos, clubes, u otras formas de organización e interacción entre estudiantes, promovidos por la institución escolar.

Los estudios previamente descritos, tienen tras de sí diferentes perspectivas teóricas inscritas en algunos campos disciplinarios propios de las ciencias sociales. Como se habrá advertido, en este artículo orientamos la construcción de nuestro marco categorial a partir del estructural constructivismo de Bourdieu, y de las nociones ya mencionadas. Esta elección obedece a que tanto las prácticas académicas como las culturales admiten una relación entre estructuras y agencias que está en la base de la teoría sociológica elegida.

En el plano de las estructuras sociales, tenemos a la universidad como un campo y a las disciplinas como una comunidad con sus principios normativos, sociales, culturales y simbólicos; mientras que, en el plano de la agencia social, son los estudiantes universitarios quienes experimentan un proceso de incorporación de un habitus y un sentido práctico, estratégico, que se refuerza con las prácticas llevadas a cabo en el primer año (Bourdieu, 2002, 2007).

Derivado de las reflexiones anteriores, las preguntas de investigación que están detrás de las relaciones de análisis formuladas son, en primer lugar, ¿cómo contribuyen en la conformación de un sentido práctico universitario aquellas prácticas académicas y culturales que llevan a cabo los estudiantes durante el primer año? ¿qué papel juegan las disciplinas en la promoción de las prácticas académicas y culturales en el primer año de estudios universitarios?

\section{Perspectiva metodológica y modelo de análisis}

En 2019, emprendimos un estudio cuantitativo, exploratorio y comparativo sobre las prácticas académicas y socioculturales experimentadas durante el primer año universitario por estudiantes de seis disciplinas en la Universidad Veracruzana: Sociología, Letras, Física, Ingeniería en Alimentos, Nutrición y Odontología. Mediante la técnica de censo, se aplicó a esta población escolar un cuestionario cuyas respuestas fueron anónimas.

El cuestionario exploró cinco dimensiones de análisis en los jóvenes universitarios: la sociodemográfica, la académica, la sociocultural, la de participación política y la de identidad. Cada dimensión se abordó a partir de un conjunto de preguntas cerradas, algunas de ellas dicotómicas, mientras que otras fueron diseñadas mediante una escala Likert. Los resultados presentados aquí son el producto del análisis sobre las dimensiones académica y sociocultural únicamente, 
en virtud de las relaciones ya establecidas. La población escolar fue de 318 estudiantes, distribuidos según la tabla siguiente.

Tabla 1. Distribución de la población escolar

\begin{tabular}{|c|c|c|}
\hline \multirow{3}{*}{ Disciplinas } & \multicolumn{2}{|c|}{ Aplicaciones } \\
\hline & \multicolumn{2}{|c|}{ Absolutos NT= 318} \\
\hline & Mujeres & Hombres \\
\hline Sociología & 19 & 10 \\
\hline Letras & 29 & 12 \\
\hline Física & 8 & 20 \\
\hline Ingeniería en alimentos & 14 & 14 \\
\hline Nutrición & 66 & 31 \\
\hline Odontología & 65 & 30 \\
\hline Total & 201 & 117 \\
\hline
\end{tabular}

Fuente: Elaboración propia.

La técnica en la que nos apoyamos para establecer la gradación en cada una de las tablas fue el análisis factorial. Esta técnica tiene como objetivo identificar, por medio de operaciones de correlación, una estructura subyacente entre el conjunto de variables del estudio; es decir identificar grupos de variables con alta correlación entre sí, lo cual permite realizar un estudio minucioso reduciendo la complejidad de las variables en cuestión (Martínez, Sepúlveda, 2012). Consideramos pertinente reportar estos rasgos en la medida en que buscamos que la estrategia metodológica sea coherente con las relaciones de análisis y la perspectiva teórica planteada. Aquí es donde cobra relevancia la noción de disciplina.

Becher (1997) conformó un modelo de clasificación de las disciplinas según las orientaciones epistemológicas y sociales de cada una de ellas. Como resultado de ese modelo surgieron cuatro combinaciones: la primera se designó como duras puras, y agrupa a aquellas disciplinas cuyo conocimiento se caracteriza por un crecimiento acumulativo, relativamente sostenido, y en donde la producción de nuevo conocimiento pasa por la refutación de los criterios bajo los cuales se establece. En nuestro estudio, Física representa a esta categoría. La segunda combinación se designó como duras aplicadas, en las que el conocimiento no es necesariamente acumulativo, las actividades se orientan hacia un fin práctico y son juzgadas por su eficacia. Estas disciplinas utilizan el conocimiento construido en las disciplinas duras puras (como la matemática y la física). Los resultados casi siempre son productos y técnicas (por ejemplo, las ingenierías). En nuestro estudio elegimos a Ingeniería en Alimentos, Odontología y Nutrición. A pesar de su misma ubicación, la primera tiene un fuerte componente basado en las matemáticas, la física y la química, mientras que las dos restantes son del área de la salud. 
En las disciplinas blandas puras, Becher identificó fronteras laxamente definidas hacia territorios disciplinares vecinos. El conocimiento se produce con menor consenso, y coexisten varias perspectivas sobre un mismo fenómeno social. El conocimiento puede relacionarse tanto con el pasado como con el futuro (Historia, Filosofía). La complejidad es un aspecto legítimo del conocimiento y es altamente apreciada. En nuestro estudio, elegimos a Letras. Finalmente, en el cuadrante de las disciplinas blandas aplicadas, se recurre al conocimiento blando puro como medio de comprensión y aceptación de las situaciones humanas. En estas disciplinas, las raíces intelectuales se originan en las interpretaciones reformuladas de las ciencias sociales y las humanidades. Elegimos a Sociología en el estudio; una característica de esta disciplina es que su evolución a lo largo del tiempo ha tenido lugar a partir del conocimiento producido dentro de sus propios límites, en tanto ciencia social, con relativa autonomía. Este fenómeno nos lleva a ubicarla como disciplina dura aplicada.

La elección de estas disciplinas está relacionada con un rasgo característico de la Universidad Veracruzana. En Xalapa, capital del estado, se concentra la mayor parte de la población de esta institución, y sólo en esta ciudad están representadas todas las áreas académicas. Con estos referentes describiremos el sistema categorial que ordena la información empírica.

En la dimensión académica, enfocamos las prácticas de los jóvenes en el primer año, pues éste representa nuevas formas de organización académica donde se inician o se reconfiguran prácticas que no eran comunes en el bachillerato. Las prácticas académicas se analizaron en relación con tres categorías relacionadas con las clases escolares (véase cuadro 1). Las categorías nos permitieron observar el desempeño escolar y el compromiso hacia las disposiciones establecidas en sus disciplinas.

Por su parte, en la dimensión sociocultural, se diseñaron variables relacionadas con las actividades culturales, tanto dentro como fuera del contexto escolar, para referir los usos sociales de las prácticas culturales. Lo anterior, con la idea de que la cultura se adquiere en la socialización de los agentes y en las prácticas dentro de espacios constituidos para tales fines. Se analizó el sentido estratégico de los estudiantes para vincularse con espacios culturales y sociales donde se practican habilidades artísticas probablemente antes no exploradas.

El conjunto de variables se agrupó en torno a dos acciones generales: asistir y practicar actividades culturales. Las prácticas se analizaron en cuatro categorías relacionadas tanto con el contexto escolar como el extraescolar (véase cuadro 1).

Se utilizó el software Statistical Package for the Social Sciences, SPSS por sus siglas en inglés, para realizar un análisis factorial en cada conjunto de variables que conforman las dos dimensiones (cuadro 1), con el objetivo de construir grados (alto, medio, bajo) y ponerlos en correspondencia con las disciplinas. 
Cuadro 1. Dimensiones, categorías y variables del estudio

\begin{tabular}{|c|c|c|}
\hline Dimensión & Categoría & Variables \\
\hline \multirow[t]{3}{*}{ Académica } & $\begin{array}{l}\text { Organización de las } \\
\text { actividades acadé- } \\
\text { micas }\end{array}$ & $\begin{array}{l}\text { Repasar los contenidos de clase que no se dominan, adelantar } \\
\text { lecturas para las clases siguientes, buscar información para } \\
\text { complementar contenidos en clase, avanzar en tareas durante } \\
\text { las horas libres y realizar prácticas según contenido de la clase. }\end{array}$ \\
\hline & $\begin{array}{l}\text { Participación activa } \\
\text { en las discusiones } \\
\text { de clase }\end{array}$ & $\begin{array}{l}\text { La discusión de puntos de vista con los profesores; la formula- } \\
\text { ción de preguntas en clase, la discusión de los puntos de vista } \\
\text { con los compañeros de clase y la aclaración de dudas. }\end{array}$ \\
\hline & $\begin{array}{l}\text { Cumplimiento de } \\
\text { las actividades es- } \\
\text { colares }\end{array}$ & $\begin{array}{l}\text { Seguir el discurso de los profesores, realizar trabajos escolares } \\
\text { en grupo, realizar trabajos individuales, llegar puntual a clase, } \\
\text { asistir regularmente, entregar tareas, tomar notas o apuntes. }\end{array}$ \\
\hline \multirow[t]{4}{*}{ Sociocultural } & $\begin{array}{l}\text { Asistencia y partici- } \\
\text { pación en eventos } \\
\text { culturales }\end{array}$ & $\begin{array}{l}\text { Asistencia a bibliotecas, librerías, zonas arqueológicas, concier- } \\
\text { tos de música, centros culturales, monumentos históricos, mu- } \\
\text { seos; asistencia y/o participación en actividades de teatro, artes } \\
\text { plásticas/visuales, fiestas tradicionales, danza. }\end{array}$ \\
\hline & $\begin{array}{l}\text { Socialización y ex- } \\
\text { presión cultural }\end{array}$ & $\begin{array}{l}\text { Asistencia a actividades culturales para conocer gente que } \\
\text { piensa igual, para expresarte, para desarrollar tu creatividad, } \\
\text { conocer gente que piensa de forma diferente, para estar con la } \\
\text { pareja, para estar con los amigos, solo por diversión. }\end{array}$ \\
\hline & $\begin{array}{l}\text { Actividades cultura- } \\
\text { les y espacio social }\end{array}$ & $\begin{array}{l}\text { Actividades culturales de los estudiantes en el primer año en: } \\
\text { calle, centros culturales públicos, talleres de arte, agrupaciones } \\
\text { artísticas, teatros, foros públicos, cafeterías y bares. }\end{array}$ \\
\hline & $\begin{array}{l}\text { Asistencia y partici- } \\
\text { pación en prácticas } \\
\text { culturales como } \\
\text { capital incorporado }\end{array}$ & $\begin{array}{l}\text { Prácticas culturales en casa (lectura, escritura, música), prác- } \\
\text { ticas culturales como cultivo personal, prácticas culturales con } \\
\text { miembros de la familia (habitus familiar), prácticas culturales en } \\
\text { centros culturales privados. }\end{array}$ \\
\hline
\end{tabular}

Fuente: Elaboración propia.

\section{Análisis y discusión de los resultados}

Observemos la primera categoría, la "Organización de las actividades académicas". Las variables que la conforman fueron: repasar los contenidos de clase que no se dominan, adelantar lecturas para las clases siguientes, buscar información para complementar contenidos en clase, avanzar en tareas durante las horas libres y realizar prácticas sobre la clase. La siguiente tabla resume las distribuciones obtenidas a partir de la operación con el análisis factorial. 
Tabla 2. Organización de las actividades académicas

\begin{tabular}{|c|c|c|c|c|}
\hline Disciplina/Nivel & $N$ & Bajo $^{1}$ & Medio & Alto \\
\hline Sociología & 28 & $\begin{array}{l}11 \\
39.3 \%\end{array}$ & $\begin{array}{l}9 \\
32.1 \%\end{array}$ & $\begin{array}{l}8 \\
28.6 \%\end{array}$ \\
\hline Letras & 38 & $\begin{array}{l}11 \\
28.9 \% \\
\end{array}$ & $\begin{array}{l}14 \\
36.8 \% \\
\end{array}$ & $\begin{array}{l}13 \\
34.2 \%\end{array}$ \\
\hline I. Alimentos & 27 & $\begin{array}{l}10 \\
37.0 \%\end{array}$ & $\begin{array}{l}9 \\
33.3 \% \\
\end{array}$ & $\begin{array}{l}8 \\
29.6 \% \\
\end{array}$ \\
\hline Física & 27 & $\begin{array}{l}13 \\
48.1 \%\end{array}$ & $\begin{array}{l}4 \\
14.8 \% \\
\end{array}$ & $\begin{array}{l}10 \\
37.0 \% \\
\end{array}$ \\
\hline Odontología & 90 & \begin{tabular}{|l}
12 \\
$13.3 \%$ \\
\end{tabular} & $\begin{array}{l}31 \\
34.4 \% \\
\end{array}$ & $\begin{array}{l}47 \\
52.2 \%\end{array}$ \\
\hline Nutrición & 94 & $\begin{array}{l}37 \\
39.4 \% \\
\end{array}$ & $\begin{array}{l}31 \\
33.0 \% \\
\end{array}$ & $\begin{array}{l}26 \\
27.7 \% \\
\end{array}$ \\
\hline Total & $304^{2}$ & $\begin{array}{l}94 \\
30.9 \%\end{array}$ & $\begin{array}{l}98 \\
32.2 \% \\
\end{array}$ & $\begin{array}{l}112 \\
36.8 \%\end{array}$ \\
\hline
\end{tabular}

N_T = 318. $p<.003$. Fuente: Elaboración propia.

La información expuesta refleja que la población bajo estudio usó diferentes estrategias de organización académica en relación con las clases. La variabilidad puede explicarse desde las disciplinas como comunidades que dentro de sus propias construcciones simbólicas otorgan algún valor a esta categoría. Más de la mitad de los estudiantes de Odontología (disciplina dura aplicada), se ubicaron en el nivel alto. Consideramos, por lo tanto, que esta disciplina valora de un modo diferente las estrategias de organización académica.

Según Bourdieu (2007), los modos de organización de los agentes se heredan culturalmente; son el resultado de la forma en que las familias usan el tiempo y lo orientan hacia un sentido práctico. Bajo este razonamiento, los estudiantes de esta disciplina representan en mayor medida que otras poblaciones escolares un sentido práctico en el que, por un lado, poseen como parte de su habitus la habilidad para organizar tareas, tales como buscar información, repasar contenidos, usar horas libres en prácticas académicas. Por otro lado, estas prácticas se complementan con lo que la comunidad disciplinaria toma en consideración como algo valioso. Odontología es una disciplina en la que los aspectos normativos y simbólicos (el uso de la bata blanca del personal de la salud, el reglamento de los espacios destinados a las actividades de salud, el uso del instrumental quirúrgico, entre otros) juegan un papel importante en la representación social como profesión y carrera.

1 Los niveles se establecen según las puntuaciones factoriales resultantes.

2 El total de casos del estudio (N_T) fue de 318. Sin embargo, en algunas ocasiones, al procesar la información, se perdieron algunos datos, quedando la $\mathrm{N}$ con menor número de casos. Es por ello que se representa como $\mathrm{N}=304$. Asimismo, en cada tabla reportamos la chi cuadrada, para mostrar las asociaciones estadísticas. 
Lo anterior se constata en el estudio emprendido por Canseco y Jarillo (2018), quienes, desde un análisis de representaciones sociales, encontraron que parte de las creencias relacionadas con la salud descansan en los valores de paciencia y acción-interacción-cumplimiento. La percepción de los pacientes con respecto a los profesionales de esta disciplina está mediada por la confianza en ellos, lo cual pasa necesariamente por la forma en que se les percibe dentro de este campo. Se observa así que, desde el primer año, las prácticas académicas llevadas a cabo por los estudiantes reflejan una capacidad estratégica.

En contraparte, Física (dura pura), fue la disciplina con menor porcentaje de estudiantes en el nivel bajo. En el mismo orden de ideas, podríamos suponer que aquí la organización de actividades académicas tiene menos relevancia. El sentido práctico de los estudiantes en el primer año sigue la ruta de este conjunto de prácticas. El resto de las disciplinas tuvo una distribución equilibrada, con una ligera tendencia de medio a bajo en Sociología (blanda aplicada), Ingeniería en Alimentos y Nutrición (duras aplicadas). En Letras (blanda pura) la tendencia fue de medio a alto. Esto quiere decir que no hallamos el mismo patrón de estructuración del sentido práctico en todas las disciplinas, en algunas podemos encontrar porcentajes de estudiantes con un alto nivel de prácticas académicas cumplidas en el primer año, pero las disciplinas no parecen tener la misma valoración sobre éstas.

La segunda categoría fue la "Participación activa en las discusiones de clase". Se observa el nivel de integración que los estudiantes lograron en sus respectivas disciplinas a partir de un desempeño activo en los temas relativos a los contenidos de clase. Las variables fueron: la discusión de puntos de vista con los profesores, la formulación de preguntas en clase, la discusión de los puntos de vista con los compañeros de clase y la aclaración de dudas.

Las variables se diseñaron para buscar información sobre el papel activo de los estudiantes con respecto a las dinámicas de transmisión del conocimiento. La formación disciplinaria de los estudiantes pasa por la adaptación a las prácticas pedagógicas, las cuales son referentes para el despliegue de habilidades y estrategias según las características de una clase universitaria. En la tabla 3 se muestran las distribuciones en cada población estudiantil. 
Tabla 3. Participación activa en las discusiones de clase

\begin{tabular}{|c|c|c|c|c|}
\hline Disciplina/ Nivel & $N$ & Bajo & Medio & Alto \\
\hline Sociología & 27 & $\begin{array}{l}4 \\
14.8 \%\end{array}$ & $\begin{array}{l}8 \\
29.6 \%\end{array}$ & $\begin{array}{l}15 \\
55.6 \%\end{array}$ \\
\hline Letras & 38 & $\begin{array}{l}9 \\
23.7 \% \\
\end{array}$ & $\begin{array}{l}17 \\
44.7 \% \\
\end{array}$ & $\begin{array}{l}12 \\
31.6 \%\end{array}$ \\
\hline I. Alimentos & 27 & $\begin{array}{l}11 \\
40.7 \% \\
\end{array}$ & $\begin{array}{l}6 \\
22.2 \% \\
\end{array}$ & $\begin{array}{l}10 \\
37.0 \%\end{array}$ \\
\hline Física & 27 & $\begin{array}{l}9 \\
33.3 \% \\
\end{array}$ & $\begin{array}{l}7 \\
25.9 \% \\
\end{array}$ & \begin{tabular}{|l}
11 \\
$40.7 \%$ \\
\end{tabular} \\
\hline Odontología & 91 & $\begin{array}{l}29 \\
31.9 \% \\
\end{array}$ & $\begin{array}{l}29 \\
31.9 \%\end{array}$ & $\begin{array}{l}33 \\
36.3 \% \\
\end{array}$ \\
\hline Nutrición & 94 & $\begin{array}{l}38 \\
40.4 \%\end{array}$ & $\begin{array}{l}34 \\
36.2 \%\end{array}$ & $\begin{array}{l}22 \\
23.4 \% \\
\end{array}$ \\
\hline Total & $\begin{array}{l}304 \\
100.0 \%\end{array}$ & $\begin{array}{l}100 \\
32.9 \%\end{array}$ & $\begin{array}{l}101 \\
33.2 \%\end{array}$ & $\begin{array}{l}103 \\
33.9 \%\end{array}$ \\
\hline
\end{tabular}

N_T = 318. $\mathrm{p}<.007$ Fuente: Elaboración propia.

La población total se distribuyó casi de manera equitativa en los tres niveles de esta categoría. Pero cuando incorporamos el criterio disciplinario aparecieron los matices. El caso más sobresaliente fue Sociología, donde la mayoría de los estudiantes se ubicó en el nivel más alto, dato comprensible si consideramos el papel que juega la teoría en la formación disciplinaria y en las habilidades argumentativas, de comparación, análisis, síntesis, crítica, entre otras.

La representación de los estudiantes de Sociología en el nivel alto no solo implica el intercambio de los puntos de vista con sus profesores, sino también que esa interacción conduce a la integración social con los otros miembros de la comunidad académica. Se trata de lo que Bourdieu denomina acumulación de capital social y escolar, en tanto conjunto de recursos que se adquieren dentro del espacio universitario (Bourdieu, 2007). Observamos a una disciplina en la que los estudiantes se alejan del rol tradicional de ser meros receptores del discurso de los profesores, cuestión que en el primer año no es común.

En el estudio de Soto (2021), advertimos que los estudiantes de primer año no se caracterizan por una presencia activa en clase debido al rol de recién ingresantes y al desconocimiento del contexto escolar y del aula. Es común una autopercepción que los posiciona como miembros que no dominan aún los códigos lingüísticos, académicos y pedagógicos de la disciplina. $\mathrm{A}$ esto debe sumarse el conocimiento de la disciplina en sí y sus propias ritualidades (Silva, 2012; Suárez, Vásquez, 2020).

En el caso de Letras no se produjo el mismo comportamiento que en Sociología, a pesar de que se trata de un campo de conocimiento donde la argumentación oral y escrita es una habilidad básica. La mayoría de los estudiantes se ubicaron en el nivel medio. En contraparte, 
Ingeniería en Alimentos y Nutrición tuvieron más estudiantes en el nivel bajo. Entonces, discutir los puntos de vista con los profesores, hacer preguntas durante la clase, discutir puntos de vista con los compañeros, fue menos apreciado en las disciplinas más cercanas a las ciencias duras, donde el método científico es la vía para la validación de nuevos saberes y el intercambio argumentativo está menos presente. Hay una marcada estandarización del quehacer científico (Vinck, 2014; Sanz, 2014). Los estudiantes de Física y Odontología también mostraron participación activa en clase, aunque una tercera parte de su población se ubicó en el nivel bajo. Advertimos así que entre la organización de actividades y la participación en discusiones hay notorias diferencias en el comportamiento estudiantil.

La tercera categoría, el "Cumplimiento de las actividades escolares", exploró prácticas tales como seguir el discurso de los profesores, realizar trabajos escolares en grupo, realizar trabajos individuales, llegar puntual a clase, asistir regularmente, entregar tareas, tomar notas o apuntes. Es una categoría cuya orientación es más normativa. Para algunas disciplinas carece de relevancia, mientras en otras se considera parte de sus procesos formativos.

Tabla 4. Cumplimiento de las actividades escolares

\begin{tabular}{|l|l|l|l|l|}
\hline Disciplina/ Nivel & $\mathbf{N}$ & Bajo & Medio & Alto \\
\hline Sociología & 28 & $\begin{array}{l}7 \\
25.0 \%\end{array}$ & $\begin{array}{l}16 \\
57.1 \%\end{array}$ & $\begin{array}{l}5 \\
17.9 \%\end{array}$ \\
\hline Letras & 38 & $\begin{array}{l}18 \\
47.4 \%\end{array}$ & $\begin{array}{l}11 \\
28.9 \%\end{array}$ & $\begin{array}{l}9 \\
23.7 \%\end{array}$ \\
\hline I. Alimentos & 27 & $\begin{array}{l}4 \\
14.8 \%\end{array}$ & $\begin{array}{l}12 \\
44.4 \%\end{array}$ & $\begin{array}{l}11 \\
40.7 \%\end{array}$ \\
\hline Física & 27 & $\begin{array}{l}12 \\
44.4 \%\end{array}$ & $\begin{array}{l}7 \\
25.9 \%\end{array}$ & $\begin{array}{l}8 \\
29.6 \%\end{array}$ \\
\hline Odontología & 91 & $\begin{array}{l}27 \\
29.7 \%\end{array}$ & $\begin{array}{l}22 \\
24.2 \%\end{array}$ & $\begin{array}{l}42 \\
46.2 \%\end{array}$ \\
\hline Nutrición & 93 & 32 & 33 & 28 \\
& & $34.4 \%$ & $35.5 \%$ & $30.1 \%$ \\
\hline Total & 304 & $\begin{array}{l}100 \\
32.9 \%\end{array}$ & $\begin{array}{l}101 \\
33.2 \%\end{array}$ & $\begin{array}{l}103 \\
33.9 \%\end{array}$ \\
\hline
\end{tabular}

N_T = 318. $\mathrm{p}<.003$ Fuente: Elaboración propia.

Odontología tuvo la representación más alta de estudiantes. Contrasta con la baja proporción en Sociología y Letras en este nivel. Odontología fue una disciplina donde la organización de actividades escolares (primera categoría) y el cumplimiento de las mismas (categoría presente) predominaron en la formación profesional de los estudiantes en el primer año, no así la discusión en clase (segunda categoría). Su distribución admite el mismo argumento que en la primera categoría; sin embargo, hay que considerar que en este conjunto de variables aparece también el uso 
del tiempo y, sobre todo, la importancia que tiene en esta disciplina cumplir con lo establecido escolarmente. Lo mismo ocurre con Ingeniería en Alimentos, donde los estudiantes obtuvieron la segunda mayor representación.

Tenemos así que en estas dos disciplinas -Física e Ingeniería en Alimentos- el modo para conformar un sentido práctico e incorporar la estructura simbólica que está detrás de las prácticas académicas descansa en cumplir con las disposiciones normativas. Según Bourdieu (2007), estas son dos condiciones para la constitución de un habitus y dos referentes básicos en la estructura social de los agentes, como ya se apuntó en el apartado teórico.

Al menos tres estudios muestran que las prácticas académicas, vistas a través del cumplimiento de las tareas, son un medio para la integración al medio escolar, la conformación de un sentido práctico y el desciframiento de las reglas de juego escolar (De Garay, 2017; Silva, 2012; Tevis, 2020). A pesar de su carácter normativo, esta categoría se complementa con las previas para dar un panorama suficientemente amplio de la dimensión académica.

En el caso de Sociología, los estudiantes tuvieron una de las representaciones más bajas en el cumplimiento de las actividades escolares, lo cual muestra nuevamente que en esta disciplina tiene más valor participar en las discusiones que cumplir con disposiciones normativas. Algo similar ocurrió con Letras, la más baja de todas. El hecho de que estas dos disciplinas hayan obtenido la distribución mostrada nos arroja cierto patrón de análisis. En tanto ubicadas en el cuadrante blando, correspondiente a las ciencias sociales y las humanidades, es más importante como parte de la comunidad académica la discusión e intercambio de ideas que el cumplimiento de actividades de orden organizativo y normativo.

En el caso de Nutrición, se presentó una distribución equitativa, mientras que en Física resultó interesante que la mayoría de los estudiantes se volvió a ubicar en el nivel más bajo. Estas dos disciplinas, propias del cuadrante duro aplicado y duro puro correspondientemente, parecen no dar relevancia a lo normativo, cuestión que se correlaciona con el desempeño e interés mostrado por los estudiantes en ese aspecto.

Las distribuciones obtenidas indican que las disciplinas tienen regulaciones distintas, lo cual se manifiesta en las prácticas académicas de los estudiantes. Todas las disciplinas son heterogéneas en ese sentido. El predominio de algún nivel en particular señala apenas alguna tendencia que no podemos tomar como determinante; sin embargo, la mayor inclinación hacia algún nivel en cada categoría apunta a la forma en que el conocimiento se transmite, se organiza, se produce y se integra, lo cual configura un panorama sobre cómo influye en el sentido práctico de estos actores la formación profesional y disciplinaria en el primer año.

Observemos ahora a los estudiantes desde la perspectiva sociocultural. Los apreciamos como jóvenes universitarios dentro y fuera del contexto escolar en el primer año de estudios. Las variables analizadas se establecieron con base a la asistencia y/o participación en actividades culturales, como se señaló en el apartado metodológico. 
La primera categoría fue "Asistencia y participación en eventos culturales". Las variables exploradas se diseñaron para conocer las experiencias de los estudiantes sobre la asistencia a bibliotecas, a librerías, a zonas arqueológicas, conciertos de música en general, conciertos de música clásica, centros culturales, monumentos históricos, museos, cine; la asistencia y/o participación en actividades de teatro, artes plásticas/visuales, festividades tradicionales, danza. Todas ellas en relación con la escuela, ya sea promovidas por la institución o por grupos relacionados con la disciplina en particular.

Tabla 5. Asistencia y participación en eventos culturales

\begin{tabular}{|c|c|c|c|c|}
\hline Disciplina/ Nivel & $\mathbf{N}$ & Bajo & Medio & Alto \\
\hline Sociología & $\begin{array}{l}29 \\
100 \%\end{array}$ & $\begin{array}{l}8 \\
27.6 \%\end{array}$ & $\begin{array}{l}8 \\
27.6 \%\end{array}$ & $\begin{array}{l}13 \\
44.8 \%\end{array}$ \\
\hline Letras & $\begin{array}{l}41 \\
100 \%\end{array}$ & $\begin{array}{l}8 \\
19.5 \%\end{array}$ & $\begin{array}{l}11 \\
26.8 \%\end{array}$ & $\begin{array}{l}22 \\
53.7 \%\end{array}$ \\
\hline I. Alimentos & $\begin{array}{l}28 \\
100 \%\end{array}$ & $\begin{array}{l}5 \\
17.9 \%\end{array}$ & $\begin{array}{l}14 \\
50.0 \%\end{array}$ & $\begin{array}{l}9 \\
32.1 \%\end{array}$ \\
\hline Física & $\begin{array}{l}28 \\
100 \%\end{array}$ & $\begin{array}{l}11 \\
39 \cdot 3 \%\end{array}$ & $\begin{array}{l}6 \\
21.4 \%\end{array}$ & $\begin{array}{l}11 \\
39 \cdot 3 \% \\
\end{array}$ \\
\hline Odontología & $\begin{array}{l}95 \\
100 \%\end{array}$ & $\begin{array}{l}39 \\
41.1 \%\end{array}$ & $\begin{array}{l}32 \\
33.7 \%\end{array}$ & $\begin{array}{l}24 \\
25 \cdot 3 \% \\
\end{array}$ \\
\hline Nutrición & $\begin{array}{l}96 \\
100 \%\end{array}$ & $\begin{array}{l}40 \\
41.7 \%\end{array}$ & $\begin{array}{l}40 \\
41.7 \%\end{array}$ & $\begin{array}{l}16 \\
16.7 \%\end{array}$ \\
\hline Total & $\begin{array}{l}317 \\
100 \%\end{array}$ & $\begin{array}{l}111 \\
35.0 \%\end{array}$ & $\begin{array}{l}111 \\
35.0 \%\end{array}$ & $\begin{array}{l}95 \\
30.0 \%\end{array}$ \\
\hline
\end{tabular}

La transición entre el bachillerado y la universidad es un periodo de cambios y adaptaciones académicas, sociales y culturales. La universidad es un espacio donde los jóvenes entran en contacto con diferentes expresiones culturales promovidas por los propios pares o por la institución escolar. Los estudiantes encuentran la posibilidad de consumos culturales diversos según la relevancia que las disciplinas les otorgan (De Garay, 2016; Duche, Andía, 2019).

En la distribución de la tabla 5, Letras tuvo a más de la mitad de sus estudiantes en el nivel alto de consumo cultural escolar. El valor que esta disciplina otorga a la asistencia y participación en actividades culturales se origina en el análisis de textos literarios, periodísticos, ensayo, entre otros, donde la discusión e intercambio de puntos de vista es fundamental, y las expresiones de la cultura conforman los objetos de estudio disciplinares.

De acuerdo con lo anterior, en una disciplina como Letras, la formación de un sentido práctico pasaría necesariamente por los aspectos de orden cultural, de manera que las prácticas desplegadas por los estudiantes encuentran aquí un correlato con esta comunidad académica. En términos de Bourdieu (2009), Letras es una disciplina que tiende a reflejar cómo las dinámicas so- 
ciales se relacionan con las épocas y los movimientos artísticos en la lógica de un campo que está estructurado en el polo dominado en relación con el poder en las sociedades contemporáneas.

El consumo cultural escolar se representó distinto en los casos de Odontología y Nutrición (duras aplicadas), con objetos de estudio referentes a la salud. Las disciplinas de Ingeniería en Alimentos (dura aplicada) y Física, (dura pura) ubicaron a más estudiantes en el nivel alto que las disciplinas de la salud, aunque en menor medida que en Letras. En Sociología destacó un porcentaje de estudiantes en el nivel alto de asistencia y participación de actividades culturales. ¿Quiere decir esto que las expresiones culturales, en tanto espacios de formación y socialización, son valoradas sólo en algunas disciplinas?

Las disciplinas priorizan el conocimiento disciplinario en la formación profesional; sin embargo, las instituciones, como en el caso de la Universidad Veracruzana, promueven eventos para el consumo cultural: talleres de pintura, diseño, apreciación del cine, dibujo artístico, escultura, música, entre otros. Hay programas que asignan créditos curriculares en actividades de tipo cultural, como la asistencia a conciertos de la Orquesta Sinfónica y la divulgación científica. Las actividades culturales son recursos para propiciar una formación disciplinar más sólida, pero no son consumidas de manera homogénea. En última instancia, el consumo cultural es el reconocimiento de un conjunto de actividades simbólicas que están en medio de una relación en la cual se requiere quién las reconozca y quién las produzca.

Veamos ahora la categoría "Socialización y expresión cultural". Explora el sentido que los estudiantes dieron a las experiencias relacionadas con las actividades culturales: asistencia a actividades culturales para conocer gente que piensa igual, para expresarse, para desarrollar la creatividad, conocer gente que piensa de forma diferente, para estar con la pareja, para estar con los amigos, sólo por diversión. 
Tabla 6. Socialización y expresión cultural

\begin{tabular}{|l|l|l|l|l|}
\hline Disciplina/Nivel & $\mathbf{N}$ & Bajo & Medio & Alto \\
\hline \multirow{2}{*}{ Sociología } & 18 & 7 & 5 & 6 \\
& $100.0 \%$ & $38.9 \%$ & $27.8 \%$ & $33.3 \%$ \\
\hline \multirow{2}{*}{ Letras } & 31 & 16 & 9 & 6 \\
& $100.0 \%$ & $51.6 \%$ & $29.0 \%$ & $19.4 \%$ \\
\hline \multirow{2}{*}{ I. Alimentos } & 13 & 9 & 2 & 2 \\
& $100.0 \%$ & $69.2 \%$ & $15.4 \%$ & $15.4 \%$ \\
\hline \multirow{2}{*}{ Física } & 11 & 5 & 3 & 3 \\
& $100.0 \%$ & $45.5 \%$ & $27.3 \%$ & $27.3 \%$ \\
\hline \multirow{2}{*}{ Odontología } & 38 & 10 & 14 & 14 \\
& $100.0 \%$ & $26.3 \%$ & $36.8 \%$ & $36.8 \%$ \\
\hline \multirow{2}{*}{ Nutrición } & 34 & 4 & 15 & 15 \\
& $100.0 \%$ & $11.8 \%$ & $44.1 \%$ & $44.1 \%$ \\
\hline Total & 145 & 51 & 48 & 46 \\
& $100.0 \%$ & $35.2 \%$ & $33.1 \%$ & $31.7 \%$ \\
\hline
\end{tabular}

N_T=318. $\mathrm{p}<.001$ Fuente: Elaboración propia.

Para Pöllman (2016), las actividades de consumo cultural promueven la interacción con otras expresiones culturales, lo cual deviene en la adquisición de un habitus intercultural. Las actividades culturales propician un sentido práctico en el cual participan los estudiantes como actores que en un espacio social ponen en juego una estructura social.

En esta categoría, los sujetos son el eje central para aprender y adquirir conocimientos. El espacio, el tiempo y las prácticas sociales son el soporte de las formas simbólicas de cultivación de la naturaleza humana. La cultura está acompañada de procesos y prácticas que otorgan sentido a través de la configuración de ideas estructuradas socialmente por las instituciones. En la escuela, las disciplinas impulsan tales prácticas como vinculación social.

El uso social de lo cultural presentó un perfil de los estudiantes que rompió con lo mostrado hasta ahora. Nutrición, que en el consumo cultural escolar tuvo los niveles más bajos, dio un giro hacia el nivel alto. Los estudiantes de esta disciplina habían mostrado hasta ahora distribuciones equitativas en prácticamente todas las categorías; sin embargo, han reportado una alta participación en diversos escenarios sociales. El hecho de que aparezca esta nueva tendencia dentro de esta disciplina, se explica en parte debido a la condición juvenil de los estudiantes, quienes más allá de las regulaciones normativas del contexto escolar, expresan su agencia mediante lo sociocultural. Los estudiantes generan encuentros y prácticas culturales como formas de agrupación juvenil, lo cual coincide con dos de los estudios identificados en el estado del arte (Serna et al., 2018; Epp et al., 2020).

La contraparte de Nutrición fue Ingeniería en Alimentos, donde se reportó el porcentaje más bajo de todas las poblaciones estudiadas. Por su parte, llama la atención que, en Letras, 
más de la mitad de los estudiantes estén ubicados en nivel bajo en la categoría. Como hemos mencionado, en Letras el consumo cultural escolar es practicado con fines de formación más que con fines de socialización. Finalmente, los estudiantes de Física y los estudiantes de Sociología comparten esta tendencia.

Uno de los aportes de la teoría estructural constructivista consiste en darle un peso explicativo a los distintos tipos de capital (social, cultural, simbólico, entre otros), así como a las relaciones y experiencias que tienen lugar dentro de los diferentes campos en los que se despliega la agencia social. En el campo educativo, particularmente en los subcampos disciplinarios, estos tipos de capital se valoran de distinto modo. La acumulación de cada uno de ellos depende del tipo de prácticas y la orientación que éstas sigan, por lo que, siguiendo esta reflexión, observamos que hay una desigual valoración en la cual los estudiantes de Nutrición aparecen como aquellos quienes representan la estrategia de usar el espacio social desde lo juvenil para integrarse en el primer año de estudios.

En lo que respecta a la categoría "Actividades culturales y espacio social", se diseñaron variables para conocer los espacios extraescolares donde se practicaron las actividades culturales de los estudiantes: en la calle, centros culturales públicos, talleres de arte, con agrupaciones artísticas, en teatros y foros habilitados para funciones públicas, en cafeterías y bares. El espacio es simbólico, y aporta referencias sobre el sentido y la disposición para la práctica.

Tabla 7. Actividades culturales y espacio social

\begin{tabular}{|l|l|l|l|l|}
\hline Disciplina/ Nivel & $\mathbf{N}$ & Bajo & Medio & Alto \\
\hline Sociología & 20 & 5 & 8 & 7 \\
& $100.0 \%$ & $25.0 \%$ & $40.0 \%$ & $35.0 \%$ \\
\hline \multirow{2}{*}{ Letras } & 30 & 13 & 12 & 5 \\
& $100.0 \%$ & $43.3 \%$ & $40.0 \%$ & $16.7 \%$ \\
\hline \multirow{2}{*}{ Física } & 13 & 7 & 0 & 6 \\
\hline \multirow{2}{*}{ Odontología } & $100.0 \%$ & $53.8 \%$ & $0.0 \%$ & $46.2 \%$ \\
\hline \multirow{2}{*}{ Nutrición } & 11 & 3 & 2 & 6 \\
& $100.0 \%$ & $27.3 \%$ & $18.2 \%$ & $54.5 \%$ \\
\hline Total & 34 & 12 & 12 & 14 \\
& $100.0 \%$ & $35.3 \%$ & $38.2 \%$ & $26.5 \%$ \\
\hline & 146 & $31.6 \%$ & $31.6 \%$ & $36.8 \%$ \\
\hline & $100.0 \%$ & $35.6 \%$ & $32.2 \%$ & $32.2 \%$ \\
\hline
\end{tabular}

Las actividades culturales extraescolares fueron más frecuentes en las disciplinas duras puras y duras aplicadas. El caso de Física fue el más notable: más de la mitad de sus estudiantes 
experimentaron actividades culturales fuera de la escuela. Los estudiantes de Física e Ingeniería en Alimentos invirtieron más tiempo en prácticas culturales externas a la escuela, incluso por encima de Letras y Sociología, ambas orientadas a las prácticas escolares internas. Si en esa comparación incorporamos a las disciplinas de la salud, se forman tres pequeños grupos a partir de los porcentajes obtenidos en el nivel alto: primero Física e Ingeniería en Alimentos; segundo Odontología y Sociología, después Nutrición y Letras.

Las distribuciones presentadas reorientan el análisis previo, lo cual se explica porque, en tanto prácticas externas a la escuela, eluden en cierto modo algunas regulaciones disciplinarias. No obstante, la socialización que se genera en estas actividades guarda alguna relación con la escuela.

La llegada de los estudiantes a las universidades a menudo se traduce en una nueva manera de entrar en socialización con diferentes grupos, así como de apropiarse de nuevos espacios aun cuando estén fuera del contexto escolar. Hay que recordar que un fenómeno presente en la mayoría de las escuelas públicas en nuestro país es la representación de estudiantes que proceden de localidades alejadas de la ciudad en la que se ubica la carrera a la que se ingresó. Esto quiere decir que los estudiantes exploran también espacios relacionados con la ciudad, así como la oferta cultural existente fuera de la escuela.

Algunos autores han dedicado sus estudios a este fenómeno y han identificado que el primer año universitario no sólo es un espacio para vivir experiencias en torno a la escuela sino, como apuntábamos al inicio de este artículo, el periodo de muchas de las "primeras veces" (Saraví, 2017; Radakovich, Wortman, 2019).

La última categoría que exploramos fue la de "Asistencia y participación en prácticas culturales como capital incorporado". Agrupó las variables prácticas culturales en casa, prácticas culturales como cultivo personal, prácticas culturales como habitus familiar y prácticas culturales en centros culturales privados.

El capital cultural incorporado es el resultado de la inversión de tiempo de los agentes en actividades, prácticas, experiencias vividas por ellos, que no son heredadas ni transmitidas genéticamente. Está asociado al origen social (Bourdieu, 2007). Se trata de experiencias cultivadas en espacios como la casa (la lectura, la escritura, la pintura, la música) y, en general, no tienen una relación directa con las disciplinas (excepto en algunas como Letras en el caso de la lectura). También se relaciona con eventos culturales de consumo habitual desde la infancia. Estas dos características distinguen a esta categoría del resto. 
Tabla 8. Asistencia y participación en prácticas culturales como capital incorporado

\begin{tabular}{|l|l|l|l|l|}
\hline Disciplina /Nivel & $\mathbf{N}$ & Bajo & Medio & Alto \\
\hline \multirow{2}{*}{ Sociología } & 20 & 6 & 7 & 7 \\
& $100.0 \%$ & $30.0 \%$ & $35.0 \%$ & $35.0 \%$ \\
\hline \multirow{2}{*}{ Letras } & 31 & 17 & 6 & 8 \\
& $100.0 \%$ & $54.8 \%$ & $19.4 \%$ & $25.8 \%$ \\
\hline \multirow{2}{*}{ I. Alimentos } & 13 & 5 & 3 & 5 \\
& $100.0 \%$ & $38.5 \%$ & $23.1 \%$ & $38.5 \%$ \\
\hline \multirow{2}{*}{ Física } & 11 & 4 & 3 & 4 \\
& $100.0 \%$ & $36.4 \%$ & $27.3 \%$ & $36.4 \%$ \\
\hline \multirow{2}{*}{ Odontología } & 39 & 15 & 11 & 13 \\
& $100.0 \%$ & $38.5 \%$ & $28.2 \%$ & $33.3 \%$ \\
\hline \multirow{2}{*}{ Nutrición } & 34 & 6 & 16 & 12 \\
& $100.0 \%$ & $17.6 \%$ & $47.1 \%$ & $35.3 \%$ \\
\hline Total & 148 & 53 & 46 & 49 \\
& $100.0 \%$ & $35.8 \%$ & $31.1 \%$ & $33.1 \%$ \\
\hline \multicolumn{5}{|l|}{$\mathrm{N}$ - $318 . \mathrm{p}<.288$ Fuente: Elaboración propia. }
\end{tabular}

Cuando los estudiantes ingresan a la universidad están habituados a determinadas prácticas en el contexto de sus grupos de pertenencia. Como hemos visto, al formar parte de su disciplina en la universidad requieren estrategias para atender las demandas de la escuela y continuar tales prácticas antecedentes. Coexisten, pues, prácticas propias del espacio externo y aquellas relativas a las demandas del campo escolar.

El rasgo más destacado en las distribuciones de la tabla 8 fue la simetría que hubo en casi todas las disciplinas (exceptuando Letras) en cuanto al porcentaje que representa a los estudiantes en el nivel alto de capital incorporado. Estamos ante una población disciplinar en la que casi una tercera parte manifestó llevar a cabo actividades que se asocian con la práctica personal de la cultura, asociada al origen familiar y cultivada en diferentes ámbitos.

Aun cuando el espacio universitario pone al servicio de su comunidad estudiantil actividades culturales, no todas las disciplinas atienden a esa oferta cultural. Sin embargo, los estudiantes con cierto nivel de capital incorporado encuentran espacios, inversión de tiempo y una socialización ligada a lo cultural como parte de una formación personal. Los estudiantes usan estas prácticas para generar su propio conocimiento, e incluso para orientarlas hacia el ocio y la recreación.

Los agentes crean estrategias de integración dentro y fuera de la escuela para construir su experiencia escolar (De Garay, 2017; Saraví, 2017; Duche, Andía, 2020); lo hacen en espacios propicios para el desarrollo de diversas formas de capital cultural que se reflejan en el consumo de actividades culturales. Los planos interno y externo en relación con la escuela complejizan la relación de los estudiantes con las disciplinas. El capital incorporado se articula con lo académico y lo cultural, y el primer año se confirma como el escenario de todas estas intervenciones. 


\section{Conclusiones}

A través de la perspectiva estructural constructivista y con la técnica de análisis factorial, en este artículo estudiamos dos relaciones de análisis construidas a modo de problema de investigación. La primera se refirió a la forma en que los estudiantes experimentaron el primer año universitario en las disciplinas de adscripción, a través de una serie de prácticas académicas. La segunda se refirió a cómo se expresó la dimensión sociocultural tanto dentro como fuera del contexto escolar, vista a través de prácticas de consumo cultural.

Las dos relaciones de análisis tienen como trasfondo una construcción más compleja, que articula las nociones teóricas derivadas de la perspectiva de Bourdieu con las diversas categorías diseñadas para observar las prácticas de los estudiantes en el primer año: el sentido práctico de los estudiantes se adquiere, construye e incorpora a través de las diversas experiencias que ellos viven en el primer año de estudio, las cuales conducen a la apropiación de los espacios sociales, culturales, académicos y simbólicos en el contexto de cada una de las disciplinas a las cuales ellos pertenecen. Consideramos que esta es la principal aportación de nuestro estudio como resultado del análisis de cada categoría. Desde luego, en cada comunidad disciplinaria hay acuerdos, ritos, creencias, en suma, modos de valorar lo académico, lo cultural y lo simbólico, cuestión que pudo ilustrarse con más detalle en la descripción de cada conjunto de variables.

De acuerdo con lo anterior y con respecto a las preguntas de investigación, podemos concluir que ambas forman parte del mismo razonamiento; es decir, no se pueden abordar separadamente. La primera pregunta de investigación formulada, a saber, ¿cómo contribuyen en la conformación de un sentido práctico universitario aquellas prácticas académicas y culturales que llevan a cabo los estudiantes durante el primer año?, tiene sentido en la medida en que respondemos también la segunda pregunta de investigación, a saber, ¿qué papel juegan las disciplinas en la promoción de las prácticas académicas y culturales en el primer año de estudios?

Observamos así que las disciplinas valoran de un modo diferente las cuestiones organizativas, normativas y referentes a la participación activa dentro de las clases escolares. Pero también establecen relaciones complejas entre lo que promueven culturalmente y aquello que los estudiantes, en tanto jóvenes pertenecientes a una estructura social, consumen culturalmente. Este hallazgo está relacionado con el concepto de campo, ya señalado en la perspectiva teórica del artículo. En tanto red de relaciones objetivas entre posiciones estructuradas históricamente por quienes participan en ese espacio social (Bourdieu, 2002), las disciplinas y sus construcciones simbólicas entran en correspondencia con los estudiantes y sus prácticas culturales, se encuentren éstas dentro o fuera del contexto escolar.

Lo anterior se muestra en cada dimensión de análisis según la forma en que las disciplinas dan sentido al desempeño de los estudiantes durante el primer año de estudios. De esta forma, en la dimensión académica, algunas disciplinas como Odontología reflejan que no es casual que sus estudiantes tiendan más que otros a posicionarse en los niveles altos de organización 
y cumplimiento de actividades escolares, pues se trata de una profesión que basa su representación social en la idea de acción-interacción-cumplimiento (Canseco, Jaramillo, 2018), característica propia de aquellas comunidades de conocimiento que pertenecen al cuadrante duro aplicado y que se ubican en las áreas de la salud (Becher, 1997).

En contraparte, las disciplinas como Sociología y, en menor medida, Letras tienden más a la participación activa en las discusiones de clase y al intercambio de los puntos de vista con los demás actores de este espacio, en virtud de que detrás de estas prácticas hay una construcción ubicada en el cuadrante blando (aplicado en Sociología y puro en Letras), de ahí que la distribución de los estudiantes muestre mayor representación que en otros grupos escolares. En ambas disciplinas, el papel de la teoría, los múltiples enfoques y perspectivas sobre sus objetos de estudio forman estudiantes más proclives a la discusión, y esa habilidad es fuertemente valorada en la formación profesional.

Si bien Física e Ingeniería en Alimentos también tuvieron una representación de más de una tercera parte de sus estudiantes en el nivel alto, si observamos la distribución de toda la población en su conjunto, advertimos que un porcentaje representativo también está ubicado en los niveles bajos, mientras que en Letras la mayoría se concentró entre los niveles medios y altos.

En lo que se refiere a la dimensión cultural entraron en juego nuevas tendencias. Podemos concluir que en esta dimensión se observó no sólo el papel de las disciplinas como contextos reguladores sino también las propiedades de agencia que están implícitas en la condición juvenil de los estudiantes universitarios. Cabe recordar que esta condición es estructurada e histórica (Reguillo, 2017; Urteaga, Moreno, 2020). De esta forma, el consumo que ellos llevaron a cabo a partir de las prácticas culturales reveló que no sólo se orienta por la escuela y su oferta cultural, sino que aparece la estructura social de origen y el capital cultural incorporado, al grado en que los estudiantes buscan sus propios espacios de expresión, pertenencia y recreación con base en las actividades artísticas y culturales, ya sea perteneciendo a grupos que las promueven o bien, asistiendo a eventos de esa naturaleza.

Es por ello que las tendencias disciplinarias que se observaron en la dimensión académica aparecieron con menos fuerza, vale decir se matizaron. En el caso de Sociología y Letras, los estudiantes consumieron eventos culturales siempre en relación con la escuela. Esto tiene que ver directamente con las características de los objetos de estudio que ambas cultivan. La cultura, en sus diferentes expresiones, es algo altamente valorado y a menudo se asigna un espacio dentro de las actividades de formación profesional a las actividades de este tipo. Pero cuando exploramos la relación entre las prácticas culturales y el sentido de socialización, en ambas disciplinas la participación en actividades dejó de ser representativa del nivel alto. Esta misma tendencia se presentó cuando exploramos las actividades culturales como parte del consumo extraescolar y como una forma de cultivo personal, producto del capital incorporado y del origen familiar, 
pues allí la representación de ambas se difuminó. Puede admitirse, entonces, que el consumo cultural es valorado siempre que sea dentro del contexto de la disciplina misma.

En cambio, las disciplinas del cuadrante duro aplicado relativas a la salud, se configuraron de otro modo. Odontología y Nutrición fueron las más bajas en cuanto al consumo cultural escolar, pero repuntaron y pasaron a ser las más altas en cuanto a consumir cultura con un sentido de socialización. Cuando se trata de actividades fuera del espacio escolar no están entre las más representativas del nivel alto; sin embargo, cuando identificamos cuántos estudiantes proceden de familias donde el capital incorporado es el que impulsa las prácticas culturales, ubican a una tercera parte de su población en el nivel alto. Odontología y Nutrición nos mostraron un perfil bastante complejo en su construcción.

Académicamente, la mayor parte de los estudiantes presentaron rasgos de organización y cumplimiento de actividades escolares, pero no tuvieron a la discusión con respecto a los contenidos de la clase como su principal elemento. Cuando exploramos la dimensión sociocultural, vemos que el consumo cultural escolar no representó a la mayoría de los estudiantes; sin embargo, cuando observamos el capital incorporado como categoría, surge la condición estudiantil y la estructura social de origen aun cuando las actividades culturales en ambas disciplinas no sean altamente valoradas. Estamos frente a la capacidad de agencia de los estudiantes ante el contexto universitario.

Finalmente, con respecto a Física e Ingeniería en Alimentos, del cuadrante duro puro y duro aplicado, advertimos dos disciplinas que no destacaron en cuanto al consumo cultural escolar. Sin embargo, pasaron a ser las más altas cuando se exploró lo relativo a las prácticas culturales fuera de la escuela. En el capital incorporado, presentaron la misma dinámica que el resto de las disciplinas.

Física e Ingeniería en Alimentos fueron muy parecidas a lo largo del análisis. Académicamente, se posicionaron entre las tres que más estudiantes reportaron en cuanto a la participación activa de los contenidos de la clase; a partir de ahí, física no pareció otorgar mucha relevancia a la organización y el cumplimiento de las actividades escolares, mientras que Ingeniería en Alimentos tuvo un porcentaje representativo del nivel alto en la categoría cumplimiento de actividades escolares. En última instancia, el acento de ambas estuvo en la discusión dentro de la dimensión académica y del consumo cultural extraescolar principalmente.

La relación entre lo académico y lo sociocultural nos reveló que cada disciplina vive de un modo distinto el primer año de estudios y produce regulaciones que los estudiantes experimentan, sin que con ello pierdan su capacidad estratégica o agencia social, sobre todo cuando algunas de las disciplinas dedican muy poca atención a las actividades culturales. Los estudiantes que tienen cierta tendencia al consumo cultural hallarán la forma de articular lo propio de la escuela, ya sea por socialización o por cultivo personal, con sus experiencias como jóvenes que viven el primer año de estudios. 
En este artículo fue pertinente identificar los mecanismos que las comunidades académicas y disciplinarias ponen en juego y que se traducen en prácticas de los estudiantes. Las disciplinas son marcos de acción disponibles para que estos actores desplieguen su capacidad estratégica de un modo que probablemente no se haya experimentado con anterioridad; es decir, en los niveles escolares previos. Analizar si los jóvenes encuentran en las disciplinas el espacio para la formación académica y cultural de acuerdo con la heterogeneidad que las caracteriza, nos permitió complejizar estos dos planos.

En última instancia, estamos frente a una diversidad de formas, rutas y medios en los cuales se construye una relación compleja entre las disciplinas, la condición juvenil de los estudiantes, las prácticas académicas y culturales, todos estos como elementos que están presentes en las diferentes maneras de construir un sentido práctico y de apropiarse de los espacios sociales universitarios durante el primer año de estudios.

\section{Referencias}

Becher, T. (1997). Tribus y territorios académicos. La indagación intelectual y la cultura de las disciplinas. España: Gedisa.

Bendit, R.; A. Miranda (2017). La gramática de la juventud: Un nuevo concepto en construcción. Última década, (6), 4-43.

Bonilla-del-Río, M.; J. Mantecón; F. Lena-Acebo (2018). Estudiantes Universitarios: prosumidores de recursos digitales y mediáticos en la era de Internet. Aula Abierta, 47(3), 319-326. https:// doi.org/10.17811/rifie.47.3.2018.319-326

Bourdieu, P. (1995). Una invitación a la sociología reflexiva. México: Siglo XXI.

Bourdieu, P. (2002). La "juventud" no es más que una palabra. Sociología y Cultura. México: Grijalbo, Conaculta.

Bourdieu, P. (2007). El sentido práctico. España: Taurus.

Bourdieu, P.; J. Passeron (2009). Los herederos: Ios estudiantes y la cultura. Buenos Aires: Siglo XXI Editores Argentina.

Canclini, N. (2012). Palabras de agradecimiento de un México a otro. En Nivon, E. (coord.). Voces híbridas. Reflexiones en torno a la obra de García Canclini. México: UAM, 9-14.

Canseco, G.; E. Jarillo (2019). Acceso y práctica odontológica en el ámbito de atención privada. Representaciones sociales y salud bucal. Revista Odontológica Mexicana, 22(3), 128-136. http://dx.doi.org/10.22201/fo.1870199xp.2018.22.3\%20Esp.68230

Carli, S. (2012). El estudiante universitario. Hacia una historia del presente de la educación pública. Buenos Aires: Siglo XXI.

De Garay, A. (2004). Integración de los jóvenes en el sistema universitario. Prácticas sociales, académicas y de consumo cultural. Barcelona: Pomares. 
De Garay, A. (2016). La integración académica y cultural a la universidad de los jóvenes universitarios. Un modelo de análisis y la implementación de políticas institucionales. Congresos CLABES III. México: UNAM, 1-12.

De Garay, A. (coord.); D. Miller; I. Montoya (2017). Las trayectorias escolares de los jóvenes en un tablero de serpientes y escaleras. México: ANUIES.

Duche, A.; B. Andía (2019). Consumo cultural de estudiantes universitarios en Perú. Un estudio comparativo. Revista de Ciencias Sociales, 25(1), 354-370.

Epp, F.; I. Hirskyj-Douglas; A. Lucero; T. Takala (2020). Identity through Social Wearables: Designing with Finnish University Students. Proceedings of the 11th Nordic Conference on Human-Computer Interaction: Shaping Experiences, Shaping Society, 1-11. https://doi. org/10.1145/3419249.3420137

Guzmán, C. (2017). Las nuevas figuras estudiantiles y los múltiples sentidos de los estudios universitarios. Revista de la Educación Superior, (182), 71-87.

Instituto Nacional de Estadística y Geografía (2012). Encuesta Nacional de Consumo Cultural de México 2012. México, INEGI. https://www.inegi.org.mx/programas/enccum/2012/default. $\underline{\mathrm{html}}$

Lee-Johnson, Y. (2015). A Qualitative Study of the Out-of-Class Learning Opportunities Constructed by Five esl Freshmen and Their Native Speaking Peers in a College Town. Journal of Ethnographic \& Qualitative Research, 10(2), 120-134.

Giesler, M.; Craig J. Thompson, C. (2016). A Tutorial in Consumer Research: Process Theorization in Cultural Consumer Research, Journal of Consumer Research, 43(4), 497-508. https://doi. org/10.1093/jcr/ucw047

Martínez, C.; M. Sepúlveda (2012). Introducción al análisis factorial exploratorio. Revista Colombiana de Psiquiatría, 41(1), 197-207. https://doi.org/10.1016/S0034-7450(14)60077-9

McEwan, B. (2011), Hybrid Engagement: How Facebook Helps and Hinders Students' Social Integration. En Wankel, L.; C. Wankel (eds.). Higher Education Administration with Social Media (Cutting-Edge Technologies in Higher Education, Vol. 2), Reino Unido: Emerald Group Publishing Limited, 3-23. https://doi.org/10.1108/S2044-9968(2011)0000002004

O'Brien, M.; V. Reetu (2019). How do First Year Students Utilize Different Lecture Resources? Higher Education, (77), 155-172. https://doi.org/10.1007/s10734-018-0250-5

Pérez, J. (2017). Las transformaciones en las edades sociales. Escuela y mercados de trabajo. En Reguillo, R. (coord.). Los jóvenes en México. México: FCE, Conaculta, 59-96.

Pöllman, A. (2016). Habitus, reflexividad y la realización del capital cultural: el potencial (no aprovechado) de la educación intercultural. Revista Educación Intercultural y Representaciones Sociales, 11(21), 55-78.

Radakovich, R.; A. Wortman (2019). Mutaciones del consumo cultural en el siglo XXI. Argentina: TESEO, ALAS, CLACSO. 
Roig, S. (2014). Bourdieu después de Bourdieu. España: Arco Libros.

Romero, A. (2020). Aproximación al consumo cultural de estudiantes universitarios de economía en Puebla, México. Última Década, 28(53), 210-234.

Reguillo, R. (coord.) (2017). Los jóvenes en México. México: FCE, Conaculta, 52-89.

Saraví, G. (2017). Juventudes fragmentadas. Socialización, clase y cultura en la construcción de la desigualdad. México: FLACSO, CIESAS.

Serna, A.; M. Hernández; Y. Sandoval; J. Manrique (2018). Prácticas de consumo cultural mediático en jóvenes estudiantes colombianos: Un estudio piloto. Dixit, (28), 22-39. https://dx.doi. org/10.22235/d.v0i28.1579

Silva, M.; A. Rodríguez (2012). El primer año universitario entre jóvenes provenientes de sectores de pobreza. Un asunto de equidad. México: ANUIES.

Soto, J. (2021). La construcción del sentido de pertenencia de los jóvenes universitarios foráneos hacia la Universidad Veracruzana en el primer año de estudios. Tesis de Maestría. México: Universidad Veracruzana. https://cdigital.uv.mx/

Suárez, H. (2017). Juventud de los estudiantes universitarios. Revista de la Educación Superior, (46), 39-54.

Suárez, J.; A. Vasquez (2020). Las expectativas de estudiantes de primer ingreso a la Universidad Veracruzana: Facultad de Pedagogía Xalapa. Revista Ciencias Pedagógicas e Innovación, 8(2), 19-27. https://doi.org/10.26423/rcpi.v8i2.378

Suárez, J.; A. Vasquez (2021). Capital cultural y trayectorias de migración interna de estudiantes de recién ingreso a la Universidad Veracruzana. Apuntes, 48(88), 125-150. https://doi. org/10.21678/apuntes.88.1277

Tevis, T.; K. Britton (2020). First-Year Student Experiences: Uncovering the Hidden Expectations of Frontline Faculty Members and Student Services Administrators. Innovative Higher Education, 45(4), 333-349.

Urteaga, M.; H. Moreno (2020). Jóvenes mexicanos: violencias estructurales y criminalización. Revista de Estudios Sociales, (73), 44-57. https://doi.org/10.7440/res73.2020.04

Vinck, D. (2014). Ciencias y sociedad. Sociología del trabajo científico. España: Gedisa. 